\title{
A highly sensitive fluorescent probe for ozone based on coumarin-benzothiazole derivative
}

\author{
Kangni Chen ${ }^{1}$, Yanbo Li $i^{2}$, Jinyan Shang ${ }^{1}$, Chao Zhao ${ }^{1}$ and Heping $\mathrm{Li}^{1^{*}}$ (D)
}

\begin{abstract}
Ozone is widely used in daily life, but studies have shown that $\mathrm{O}_{3}$ can damage human trachea and lungs, leading to diseases such as asthma, emphysema, and bronchitis. Therefore, it is of great significance to develop a simple and efficient detection method for monitoring $\mathrm{O}_{3}$ in living cells. In this study, 3-(but-3-en-1-yl)-2-(7-(but-3-en-1yloxy)-2-oxo-2H-chromen-3-yl)benzo[d]thiazol-3-ium (BCT) as a new type of water-soluble fluorescent probe was synthesized by substitution reaction of 4-bromo-1-butene and hydroxycoumarin-benzothiazole derivatives, which can specifically detect ozone in aqueous solution. The interaction of ozone on the probe can be completed within $20 \mathrm{~min}$, the fluorescence intensity is significantly enhanced, and it has the advantages of high sensitivity (detection limit $L O D=43 \mathrm{nM}$ ). The influence of $\mathrm{pH}$ on the fluorescent performance of BCT shows that the probe with super stability under weak alkali and acidic environment, which provides the necessary conditions for its detection of ozone in physiological system detection. Therefore, BCT is expected to become an effective tool for detecting ozone in cellular organisms.
\end{abstract}

Keywords: Ozone, Fluorescent detection, Coumarin-benzothiazole fluorescent probe, Photo-induced electron transfer (PET)

\section{Introduction}

As a strong oxidant, ozone $\left(\mathrm{O}_{3}\right)$ is widely used in the fields of water purification, air treatment, food preservation, deodorization, and medical treatment (Oyama 2000; Boeniger 1995; Baysan and Lynch 2005). However, there is evidence that high concentrations of $\mathrm{O}_{3}$ can damage human trachea and lungs, leading to diseases such as asthma, emphysema, and bronchitis (Kim et al. 2011; Yan et al. 2013). In 2002, Wentworth reported the ozone produced by singlet oxygen in the inflammatory response of atherosclerotic plaque and neutrophils (Wentworth Jr et al. 2002; Wentworth Jr. et al. 2003). Since then, $\mathrm{O}_{3}$ has been widely studied as an oxidant

\footnotetext{
*Correspondence: lihepinghn@126.com

'School of Chemistry and Food Engineering, Key Laboratory of Road Structure and Material of Ministry of Transport, Changsha University of Science and Technology, No.960, Wanjiali South Road, Tianxin District, Changsha City 410114, Hunan Province, China

Full list of author information is available at the end of the article
}

harmful to human health, but there is still a lack of detection methods suitable for monitoring $\mathrm{O}_{3}$ in living cells, which is not conducive to further research on the mechanism of $\mathrm{O}_{3}$ harming human health.

The current methods of detecting $\mathrm{O}_{3}$ mainly include electrochemiluminescence, bioluminescence, and chemiluminescence. For example, Takeuchi developed a chemiluminescence method using indigo-5, 5disulfonate (IDS) to identify ozone (Takeuchi and Ibusuki 1989), but it can also identify superoxide (Kettle et al. 2004). Ishii used boron-doped diamond (BDD) electrodes for electrochemical detection of ozone dissolved in water (Ishii et al. 2013). However, due to the extremely strong oxidation characteristics of ozone, the materials that can be used for sensing electrode are limited to a few precious metals and diamonds, which are expensive electrode materials. Koide's group used the mechanism of terminal olefins to specifically recognize 
ozone for the first time and designed small organic molecule probes that specifically responded to ozone (Garner et al. 2009; Leslie et al. 2011; Li et al. 2013). Compared with other detection methods, the fluorescence method has the best effect on detecting ozone. It can overcome the interference of other superoxides, thereby improve the accuracy of detection. $\mathrm{O}_{3}$ has a lower concentration and a shorter life span in living cells. Therefore, it is of great significance to develop a simple and efficient organic small molecule fluorescent probe for monitoring $\mathrm{O}_{3}$ in living cells. Among various fluorescent dyes, coumarin derivatives are widely used in the construction of selective fluorescent probes because of their advantages such as high molar extinction coefficient, high fluorescence quantum yield, and optical stability (Liao et al. 2016). Benzothiazole compounds also have good fluorescence properties due to their large conjugated system (Sun et al. 2012). Therefore, based on the coumarin-benzothiazole derivatives, combined with the mechanism of terminal olefin specific recognition of ozone, a new type of organic small molecule fluorescent probe 3-(but-3-en-1-yl)-2-(7-(but-3-en-1-yloxy)-2-oxo2H-chromen-3-yl)benzo[d] thiazol-3-ium (BCT) was constructed. Synthetic method of BCT is simple, the raw materials are readily available, and the purification treatment adopts a simple and efficient recrystallization method, which avoids heavy and inefficient column chromatography purification. The probe can quickly identify ozone and has specific selectivity to ozone, so the probe has broad application prospects in ozone detection.

\section{Materials}

The water used in the experiment was deionized. The raw materials and other reagents used for the synthesis of probes in the experiment were of analytical grade. Purchase the corresponding chemical reagents from Maclean or Aladdin. The ozone used for the detection was prepared on-site from an electrolytic ozone generator purchased from Wuhan Weimeng Environmental Protection Technology Co., Ltd, and immediately tested on-site. The ozone-dissolving solution was $10 \mathrm{mM}$ PBS buffer, and its concentration was determined by ultraviolet absorption spectrum $\left(\lambda \max =258 \mathrm{~nm} ; \varepsilon \mathrm{O}_{3}=2900 \mathrm{~L}\right.$ $\mathrm{mol}^{-1} \mathrm{~cm}^{-1}$ ) (Fan et al. 2013) and iodometric titration. Other reactive oxygen species (ROS) used in selective experiments were prepared as follows: hydrogen peroxide $\left(\mathrm{H}_{2} \mathrm{O}_{2}\right)$, sodium hypochlorite $(\mathrm{NaClO})$, and tert-butyl hydroperoxide (TBHP) are solutions of $30 \%, 10 \%$, and $70 \%$, respectively; Superoxide anion radical $\left(\mathrm{O}_{2} \bullet-\right)$ was prepared from potassium peroxide $\left(\mathrm{KO}_{2}\right)$ and dimethyl sulfoxide (DMSO); Singlet oxygen $\left({ }^{1} \mathrm{O}_{2}\right)$ was prepared from $\mathrm{NaClO}$ and $\mathrm{H}_{2} \mathrm{O}_{2}$ with a mass ratio of 1:1; The hydroxyl radical $(\bullet \mathrm{OH})$ was prepared from $\mathrm{Fe}(\mathrm{II}) \mathrm{EDTA}$;
$\mathrm{H} 2 \mathrm{O} 2$ with a mass ratio of 1:6; Prepare a $5 \mathrm{mM}$ probe stock solution by dissolving the probe in dimethyl sulfoxide (DMSO). Unless otherwise stated, the buffer solution used in the experiment was a $10 \mathrm{mM}$ PBS buffer solution.

\section{Instrumentation}

An ultraviolet-visible spectrophotometer (Shimadzu, Japan) was used to measure the ultraviolet absorption spectrum (UV-vis). The fluorescence emission spectrum was recorded using an F-7000 fluorescence spectrophotometer (Hitachi, Japan). Using TMS as an internal reference, ${ }^{1} \mathrm{H}$ NMR spectra were recorded on a Varian INOVA-400 nuclear magnetic resonance spectrometer High-resolution mass spectrum (HRMS) was performed on the LTQ Orbitrap XL massspectrometer. The $\mathrm{pH}$ value was measured using a Mettler-Toledo Delta320 $\mathrm{pH}$ meter. Other instruments include an upright rotary evaporator, SHB-III type water circulation multi-purpose vacuum pump, and X-5 micro-melting point measuring instrument.

\section{Sample preparation}

Took $4990 \mu \mathrm{L}$ of PBS buffer $(\mathrm{pH}=7.4)$ and $10 \mu \mathrm{L}$ of the prepared $5 \mathrm{mM}$ probe stock solution into a $10 \mathrm{~mL}$ ep tube, added a freshly prepared $\mathrm{O}_{3}$ aqueous solution and mixed. The excitation wavelength of the fluorescence spectrum test was $425 \mathrm{~nm}$, the excitation slit was $5 \mathrm{~nm}$, the emission slit was $5 \mathrm{~nm}$, and the photomultiplier tube voltage was $700 \mathrm{~V}$. All data were measured in parallel three times.

Test of the effect of $\mathrm{O}_{3}$ concentration on the fluorescence of probe molecules: $10 \mu \mathrm{L}$ probe $\mathrm{BCT}$ stock solution was added to 10 groups of $10 \mathrm{~mL}$ ep tubes, diluted to $5 \mathrm{~mL}$ with PBS buffer, and then $20 \mu \mathrm{L} \mathrm{O} \mathrm{O}_{3}$ aqueous solutions of different concentrations $(0,1,4,8,12,15,17$, $20,23,25 \mu \mathrm{M})$. After $10 \mathrm{~min}$ of incubation at room temperature, the UV-vis and fluorescence spectra were tested.

Selective testing of BCT probes for cations, different reactive oxygen species and amino acids: 17 groups of $10 \mu \mathrm{L}$ probe BCT stock solutions were transferred to 10 $\mathrm{mL}$ ep tubes, diluted to $5 \mathrm{~mL}$ with PBS buffer, and 0.4 $\mathrm{mL}$ of various cation aqueous solutions were added to the mixture, and the resulting mixture was shaken. Then let it stand for $10 \mathrm{~min}$, and scan each solution with a fluorescence spectrophotometer to obtain its fluorescence properties.

Test of the influence of $\mathrm{pH}$ on the fluorescence spectrum of BCT: $10 \mu \mathrm{L}$ probe BCT stock solution was added to ep tubes, diluted to $5 \mathrm{~mL}$ with PBS buffer, and the $\mathrm{pH}$ value of each solution was adjusted with dilute $\mathrm{HCl}$ and dilute $\mathrm{NaOH}$ aqueous solution to make 10 groups $\mathrm{pH} 6-8$, respectively. Then add $10 \mu \mathrm{L}$ of probe 
BCT stock solution to ep tubes, dilute to $5 \mathrm{~mL}$ with PBS buffer, then add the same amount of $\mathrm{O}_{3}$ aqueous solution with the same concentration, and adjust each ep with dilute $\mathrm{NaOH}$ and dilute $\mathrm{HCl}$ aqueous solution to make 10 groups $\mathrm{pH} 6-8$, respectively. Shake these ep tubes well and let them stand for $10 \mathrm{~min}$ at room temperature, and then test the fluorescence spectrum properties of the 20 groups of solutions.

Response time test of the action of $\mathrm{BCT}$ and $\mathrm{O}_{3}: 10 \mu \mathrm{L}$ of probe BCT stock solution was added to a $10 \mathrm{~mL}$ ep tube, diluted it to $5 \mathrm{~mL}$ with PBS buffer, and then added $0.4 \mathrm{~mL} \mathrm{O}_{3}$ solution to it. The solution was immediately transferred to a fluorescent colorimeter, used a fluorescence spectrophotometer to scan the fluorescence intensity over time.

\section{Synthesis of probe BCT}

As shown in Scheme 1, dissolve BCT-1 (295 mg, 1 $\mathrm{mmol}$ ), $\mathrm{K}_{2} \mathrm{CO}_{3}$ (120 mg, $0.91 \mathrm{mmol}$ ) and 4-bromo-1-butene (86.4 uL, 0.86 - $2 \mathrm{mmol}$ ) in $5 \mathrm{~mL}$ DMF, stir the mixture and heat to $70^{\circ} \mathrm{C}$, After the reaction proceeded for 24 hours, the mixture was poured into water $(25 \mathrm{~mL})$, and extracted with EtOAc $(40 \mathrm{~mL} \times 3)$. The combined organic layer was washed with water and brine, dried over anhydrous $\mathrm{Na} 2 \mathrm{SO} 4$, filtered and concentrated in vacuo, and the crude product was purified by recrystallization using EtOAc to obtain $0.255 \mathrm{~g}$ of a yellow solid product with a yield of $73 \%$. The ${ }^{1} \mathrm{H}$ NMR and ${ }^{13} \mathrm{C}$ NMR spectra and HRMS of BCT are given in Figures S2 and S3, respectively. ${ }^{1} \mathrm{H}$ NMR $(400 \mathrm{MHz}, \mathrm{CDCl} 3): \delta 8.53(\mathrm{~s}, 1 \mathrm{H})$, $8.40(\mathrm{~d}, \mathrm{~J}=8.9 \mathrm{~Hz}, 1 \mathrm{H}), 8.08-8.04(\mathrm{~m}, 1 \mathrm{H}), 7.85(\mathrm{~d}, \mathrm{~J}=$ $8.0 \mathrm{~Hz}, 1 \mathrm{H}), 7.49(\mathrm{~d}, \mathrm{~J}=7.2 \mathrm{~Hz}, 1 \mathrm{H}), 7.38(\mathrm{t}, \mathrm{J}=8.1 \mathrm{~Hz}$, $1 \mathrm{H}), 6.60(\mathrm{dd}, \mathrm{J}=8.9,2.3 \mathrm{~Hz}, 1 \mathrm{H}), 6.45(\mathrm{~d}, \mathrm{~J}=2.3 \mathrm{~Hz}, 1 \mathrm{H})$, 5.96-5.85 (m,2H), 5.29-5.12 (m,4H), 4.12-4.07 (m,4H), 2.67-2.62 (m,2H), 2.58-2.54 (m,2H). ${ }^{13} \mathrm{C}$ NMR (101 $\mathrm{MHz}, \mathrm{CDCl} 3): \delta 164.33,160.01,153.82,141.70,134.62$,
134.00, 130.42, 126.69, 125.68, 123.56, 121.49, 118.24, 115.11, 106.55, 102.12, 99.62, 67.80, 33.58. HRMS (ESI Positive) calc. for $\mathrm{C}_{24} \mathrm{H}_{22} \mathrm{NO}_{3} \mathrm{~S}^{+}, \quad[\mathrm{M}+\mathrm{H}]^{+} 350.0849$. found 350.0806 (Figure S1).

\section{Results and discussion}

Based on the characteristics of coumarin and benzothiazole dyes (Wang et al. 2015; Fang et al. 2019), the benzothiazole heterocycle was introduced into the 3 positions of the coumarin ring. The purpose of this design is to improve the properties of the fluorophore. The conjugation of coumarin and the benzothiazole ring leads to an increase in the conjugate system and an increase in the Stokes shift. The fluorescence emission wavelength of the probe BCT is at $550 \mathrm{~nm}$, which is 100 $\mathrm{nm}$ red-shifted compared to the common coumarin emission wavelength and emits bright green fluorescence. The introduction of 4-bromo-1-butene as the recognition group at position 7 realizes the specific recognition of ozone. The synthetic route is shown in Scheme 1. The structure of the probe BCT was characterized by HRMS (Figure S1) and NMR (Figure S2, S3).

\section{Study on spectral performance of BCT}

Ultraviolet absorption experiments were performed using aqueous solutions containing different concentrations of $\mathrm{O}_{3}$ in a PBS solution with a probe concentration of $10 \mu \mathrm{M}$ (PBS buffer: $10 \mathrm{mM}, \mathrm{pH}=7.4$ ). It can be seen from Fig. 1 that the probe $\mathrm{BCT}$ has a strong absorption peak at $425 \mathrm{~nm}$. As the ozone concentration increases, the absorbance at $425 \mathrm{~nm}$ gradually decreases, and the maximum absorption wavelength does not blue shift, which indicates that the probe molecules conjugated structure is not destroyed, it may be that ozone only reacts with the terminal ethylenic bond, causing the ether bond to break (Fig. 2).

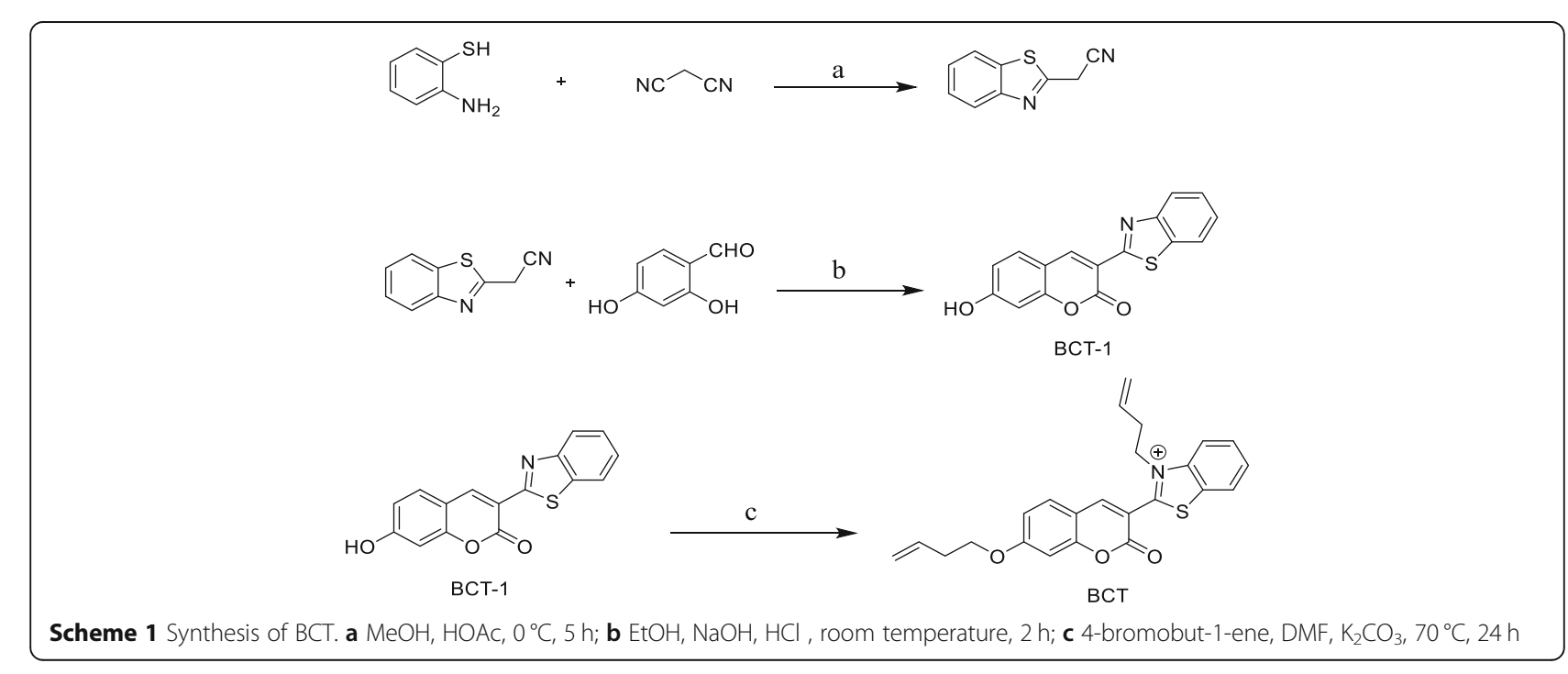




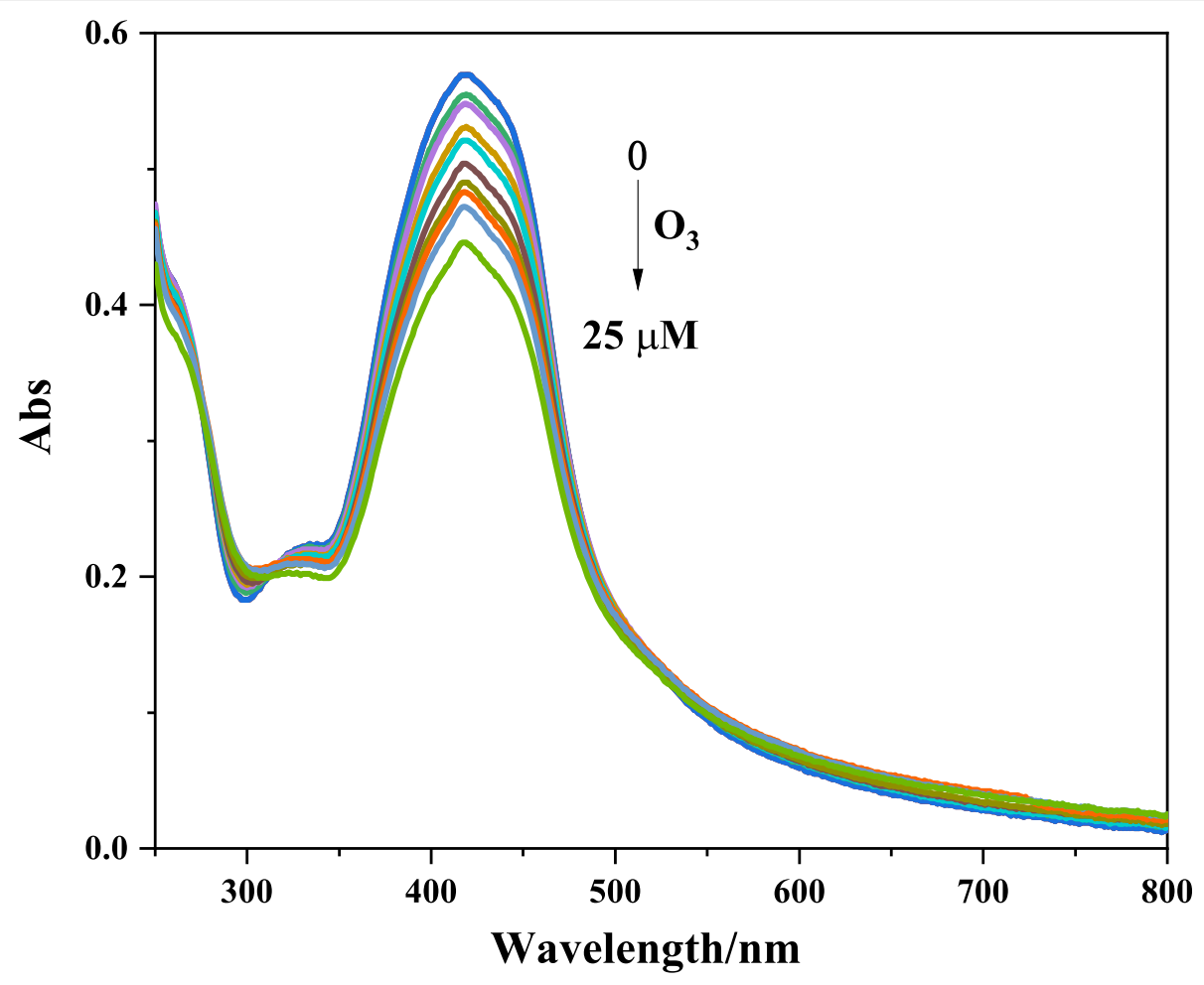

Fig. 1 Comparison of UV absorption before and after the reaction of $\mathrm{BCT}$ and $\mathrm{O}_{3}$

As shown in Fig. 3a fluorescence spectrum experiment, BCT showed weak fluorescence in PBS buffer. In the PBS buffer solution at $\mathrm{pH}=7.4$, with the increase of $\mathrm{O}_{3}$ concentration, the fluorescence intensity of BCT at $550 \mathrm{~nm}(\lambda e x=425 \mathrm{~nm})$ was significantly enhanced. We believe that the increase in fluorescence intensity is due to the break of the ether bond leading to the interruption of the photoinduced electron transfer (PET) process. When the $\mathrm{O}_{3}$ concentration reaches $25 \mu \mathrm{M}$, the fluorescence intensity reaches the plateau. The fluorescence intensity of BCT showed a good linear relationship in the range of $\mathrm{O}_{3}$ concentrations of 0 to $25 \mu \mathrm{M}$ (Fig. 3b). According to the detection limit formula LOD $=3 \sigma / \mathrm{k}$ (Where $\sigma$ is the standard deviation of the blank sample measurement, $k$ is the slope between fluorescence intensity and $\mathrm{O}_{3}$ concentration) (Zhao et al. 2020), the minimum detection concentration is calculated to be $43 \mathrm{nM}$, which indicates that the probe can be used to detect trace amounts of $\mathrm{O}_{3}$ in a physiological environment.

\section{Study on response performance of BCT}

To further study the stability of the probe BCT under different $\mathrm{pH}$ conditions, we conducted relevant fluorescence response experiments. As can be seen from Fig. 4, when no $\mathrm{O}_{3}$ aqueous solution was added, the probe $\mathrm{BCT}$ showed weak fluorescence emission in the range of pH 6.0 to 8.0. When $25 \mu \mathrm{M} \mathrm{O}_{3}$ aqueous solution was added, the BCT showed a fluorescence enhancement in<smiles>C=CCCOc1ccc2cc(-c3sc4ccccc4[n+]3CCC=C)c(=O)oc2c1</smiles>

Fig. 2 Comparison of the structure of probe $\mathrm{BCT}$ and $\mathrm{O}_{3}$ before and after the reaction 

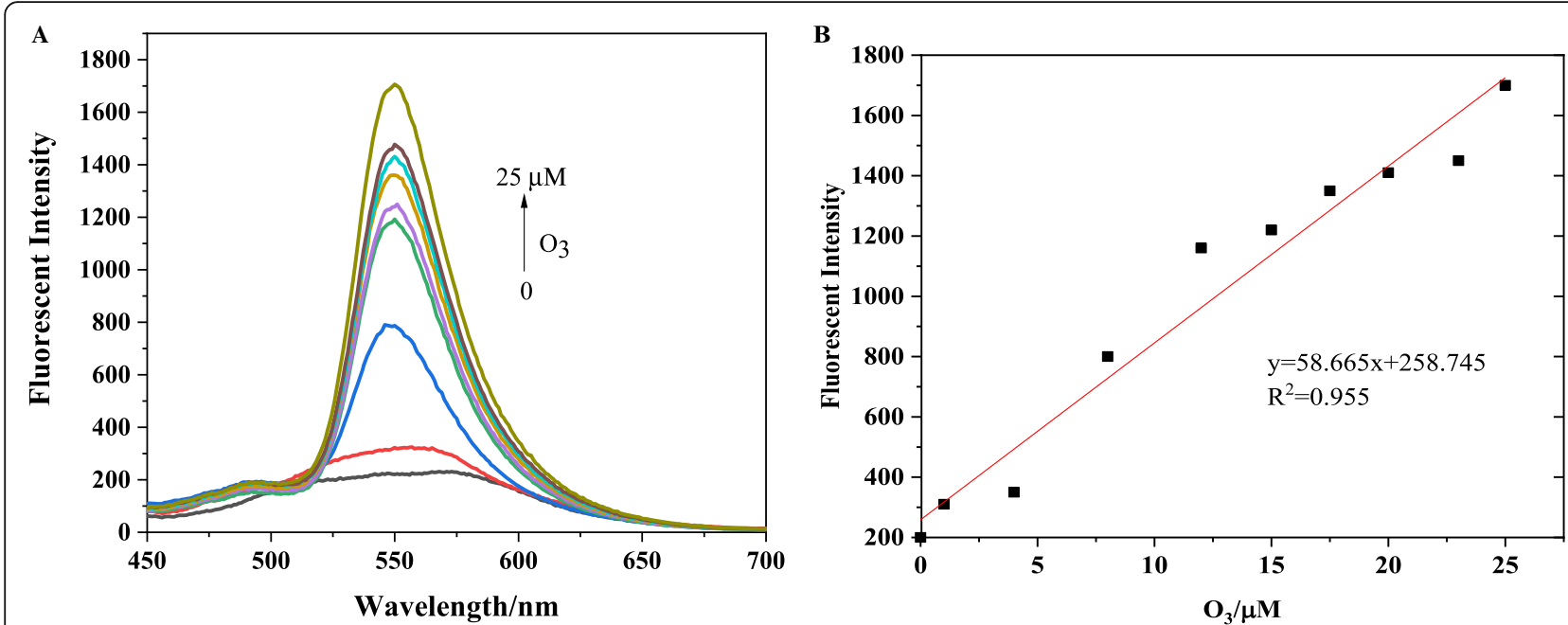

Fig. 3 Fluorescence spectrum change curve. a The spectrum of probe $\mathrm{BCT}(10 \mu \mathrm{M})$ when different concentrations of $\mathrm{O}_{3}$ aqueous solution were added to PBS buffer $(\mathrm{pH}=7.4,10 \mathrm{mM})$. $\mathbf{b}$ Linearly fit the fluorescence spectrum and calculate its minimum detection limit

the $\mathrm{pH}$ range of 6 to 8 , and there is no obvious difference in the degree of fluorescence enhancement at different $\mathrm{pH}$. This indicates that the probe is very stable in detecting $\mathrm{O}_{3}$ in a neutral environment, which indicates that the field of biosensing has a good foundation.

Response time is an important factor to evaluate the performance of fluorescent probes. To explore the reaction performance of $\mathrm{BCT}$ and $\mathrm{O}_{3}$, we used fluorescence spectroscopy to investigate the response time of the probe with 2.5 times the amount of $\mathrm{O}_{3}$. Plot the fluorescence intensity of the BCT probe at $550 \mathrm{~nm}$ peak as a function of time. As shown in Fig. 5, the fluorescence intensity can be increased to the highest within $20 \mathrm{~min}$, basically reaching plateau, which shows that the probe can complete the detection of ozone in aqueous solution in a short time.

\section{Study on the selectivity of BCT}

A probe has good selectivity for a specific analyte, which determines whether the probe can specifically recognize the analyte. This article selects common cations, active oxygen, and amino acids, including 1 : blank; $2: \mathrm{Na}^{+} ; 3$ : $\mathrm{K}^{+} ;$4: $\mathrm{Ca}^{2+} ; 5: \mathrm{Cu}^{2+} ;$ 6: $\mathrm{Fe}^{3+} ;$ 7: $\mathrm{ONOO}^{-} ; 8: \mathrm{H}_{2} \mathrm{O}_{2} ; 9:$ $\mathrm{O}_{2} \bullet^{-} ; 10: \mathrm{ClO}^{-} ; 11:{ }^{1} \mathrm{O}_{2} ; 12: \bullet \mathrm{OH} ; 13: \mathrm{NO} ; 14: \mathrm{TBHP} ; 15$ :

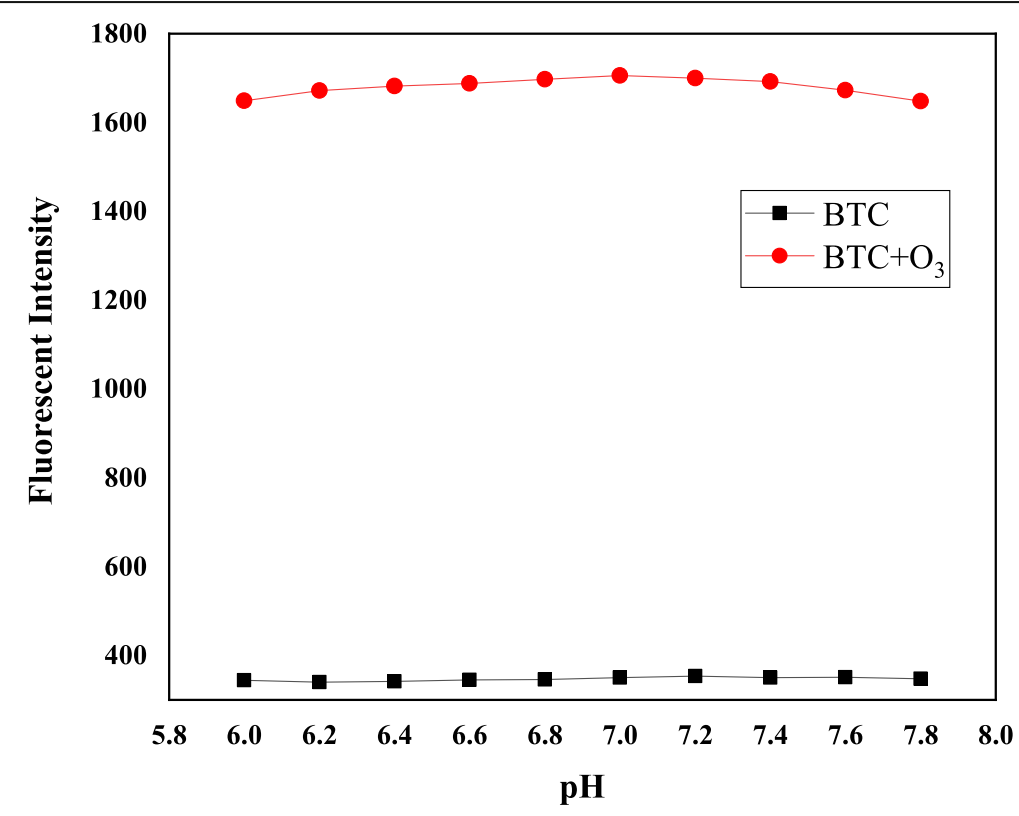

Fig. 4 Response of probe $\mathrm{BCT}(10 \mu \mathrm{M})$ to $\mathrm{O}_{3}(25 \mu \mathrm{M})$ under different $\mathrm{pH}$ conditions 


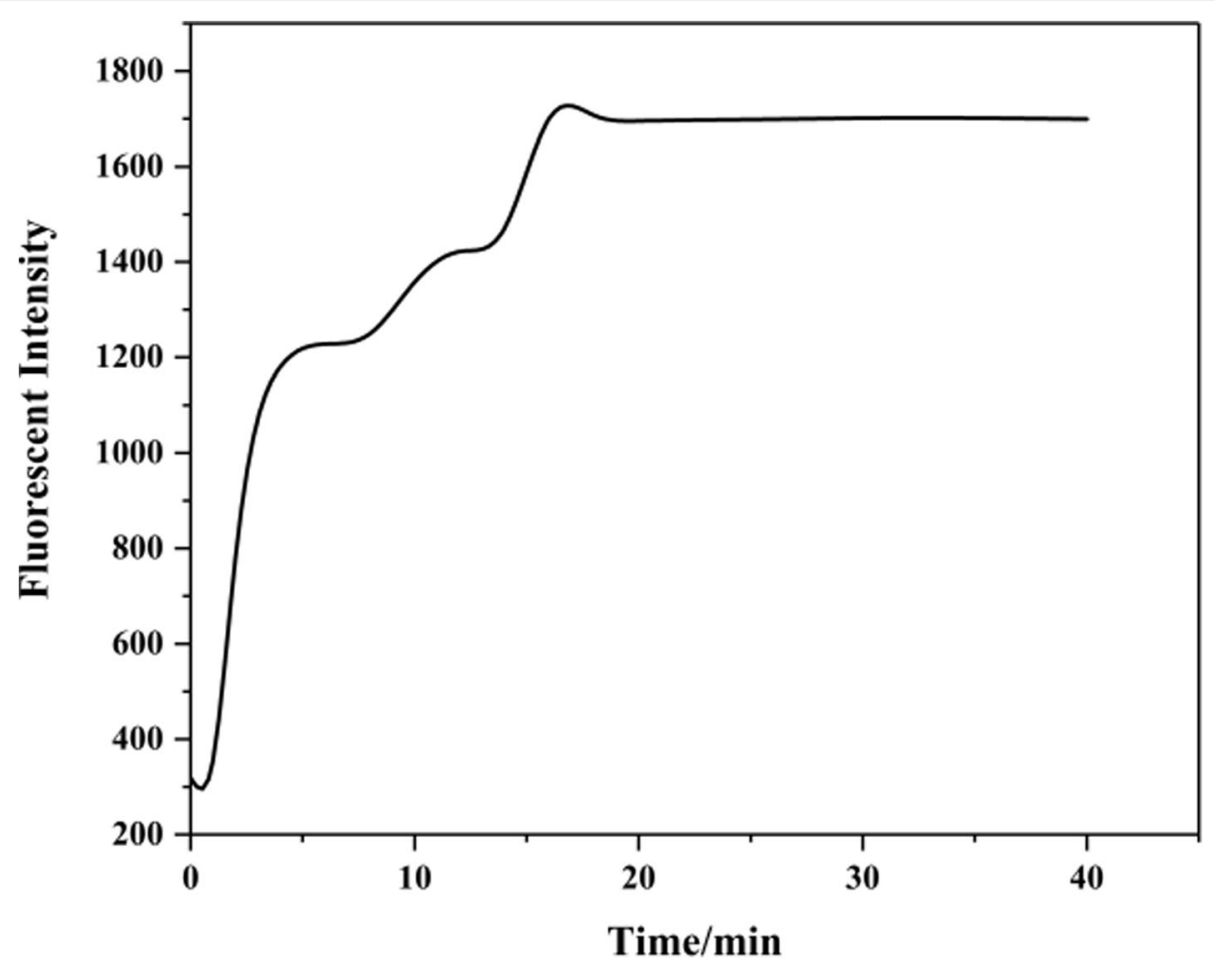

Fig. 5 Fluorescence response time of $10 \mu \mathrm{M}$ BCT in PBS buffer (10 mM, pH 7.4) to $25 \mu \mathrm{M} \mathrm{O}$ aqueous solution

GSH; 16: Cys; 17: $\mathrm{O}_{3}$. The analyte concentration is $25 \mu \mathrm{M}$. Figure $6 \mathrm{a}$ shows the specific fluorescence response of BCT to $\mathrm{O}_{3}$ in PBS buffer. Various analytes were added to the PBS buffer solution of the probe BCT, and then the fluorescence intensity at $550 \mathrm{~nm}$ was recorded. The test results show that the probe BCT has a specific selectivity for $\mathrm{O}_{3}$ and hardly reacts to other cations, reactive oxygen species, and amino acids. In the presence of various analytes, the fluorescence color of the probe $\mathrm{BCT}$ appears green fluorescence only in the presence of $\mathrm{O}_{3}$ (Fig. 6b). This result confirms that the probe BCT can be used as a specific fluorescent probe for detecting $\mathrm{O}_{3}$.

\section{Research on reaction mechanism}

According to the previous research results (Nam et al. 2016), we further deduced the possible mechanism of the interaction between the probe BCT and ozone. The structure of the probe was verified by HRMS and ${ }^{1} \mathrm{H}$ NMR. As shown in Fig. 7 , in the probe $\mathrm{BCT}$, coumarin and benzothiazole are used as signal groups, and the terminal ethylenic bond of the coumarin part is a potential $\mathrm{O}_{3}$ reaction site and also an electron acceptor, which happens to form a PET process with the electron-donor benzothiazole group. Due to the effect of PET, the fluorescence of the probe itself is weak. However, after the addition reaction between the terminal ethylenic bond of the probe $\mathrm{BCT}$ and ozone, formaldehyde and hydrogen peroxide molecules are released, and the $\beta$ elimination reaction occurs by itself. The ethylenic bond is broken, which causes the PET process to be interrupted and fluorescence is restored. This can just explain the fluorescence phenomenon after the probe $\mathrm{BCT}$ reacts with ozone.

\section{Conclusions}

A new water-soluble fluorescent probe BCT was synthesized by a substitution reaction of 4-bromo-1-butene and hydroxycoumarin derivatives, which can detect ozone in aqueous solution. The structure of the probe BCT was confirmed by NMR and HRMS characterization, which indirectly verified its mechanism of action. The substitution reaction of 4-bromo1-butene with the phenolic hydroxyl group of the coumarin derivative removes one molecule of $\mathrm{HBr}$ to form a weakly fluorescent probe molecule BCT. According to the specific reaction between ozone and terminal olefin, through the process of ozone cyclization, $\beta$-elimination, and intermediate hydrolysis, coumarin derivatives with strong fluorescence are obtained. We conducted further research on it and found that the probe has excellent performances such 


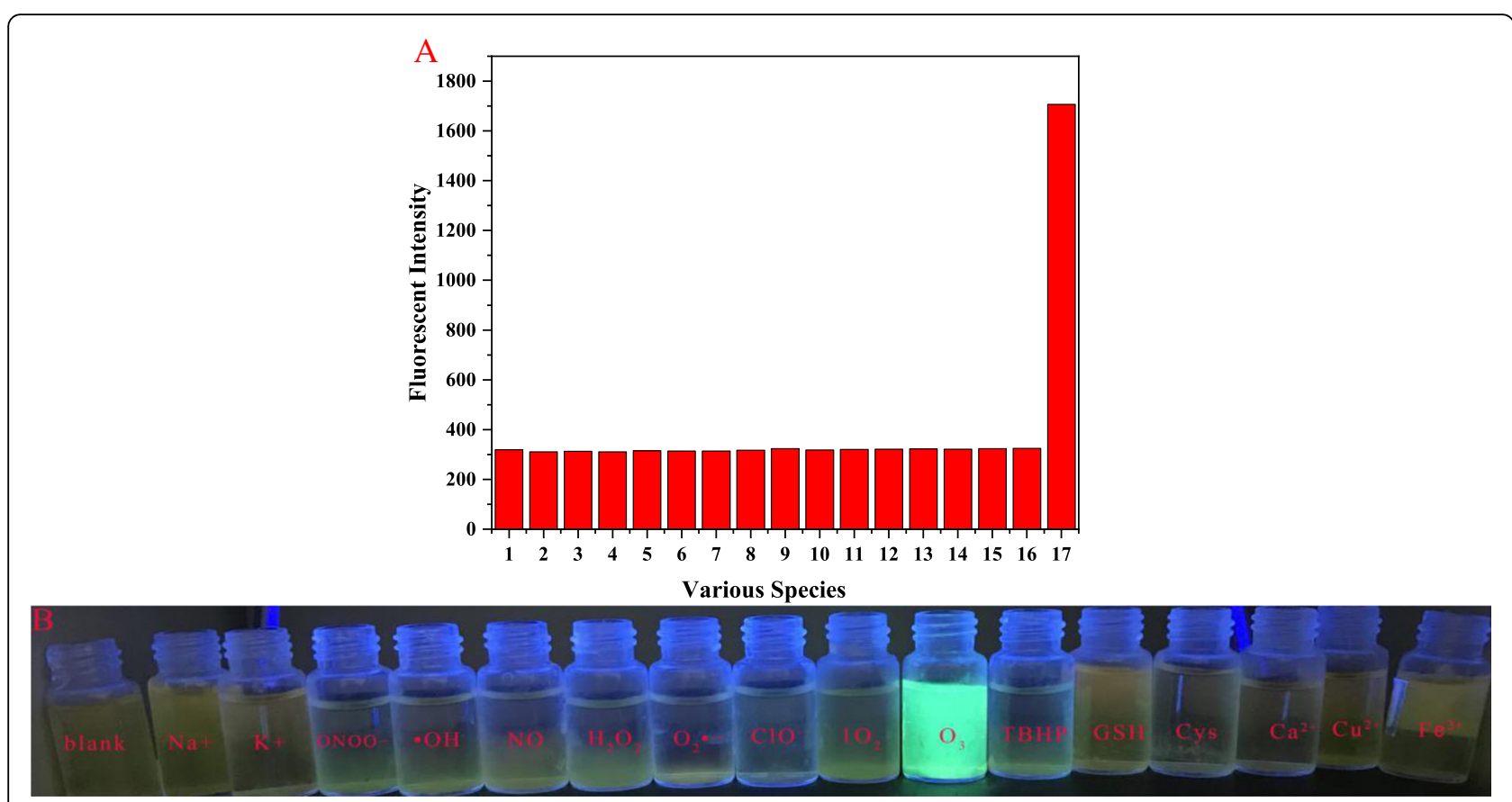

Fig. 6 a Fluorescence intensity change of the probe $B C T(10 \mu \mathrm{M})$ in PBS aqueous buffer $(10 \mathrm{mM}, \mathrm{pH}=7.4)$ after reacting with each analyte. $\mathbf{b}$ Probe $\mathrm{BCT}(10 \mu \mathrm{M})$ at $\mathrm{O}_{3}$ (1.0 equivalent) and other anions (10.0 equivalents) in PBS solution ( $\mathrm{pH}=7.4,10 \mathrm{mM}$ ) under the ultraviolet light fluorescence photo

as high sensitivity, strong specificity, and fast response speed. Through the fluorescence experiment, the effect of $\mathrm{O}_{3}$ on the probe can be completed within 20 min, the fluorescence intensity is significantly enhanced, and the detection limit is as low as $43 \mathrm{nM}$. More importantly, the probe shows super stability under weak alkali and acidic environment, which provides the necessary conditions for its detection of $\mathrm{O}_{3}$ in physiological systems.

\section{Availability of data and materials}

All experiments were conducted in the School of Chemistry and Food Engineering, Changsha University

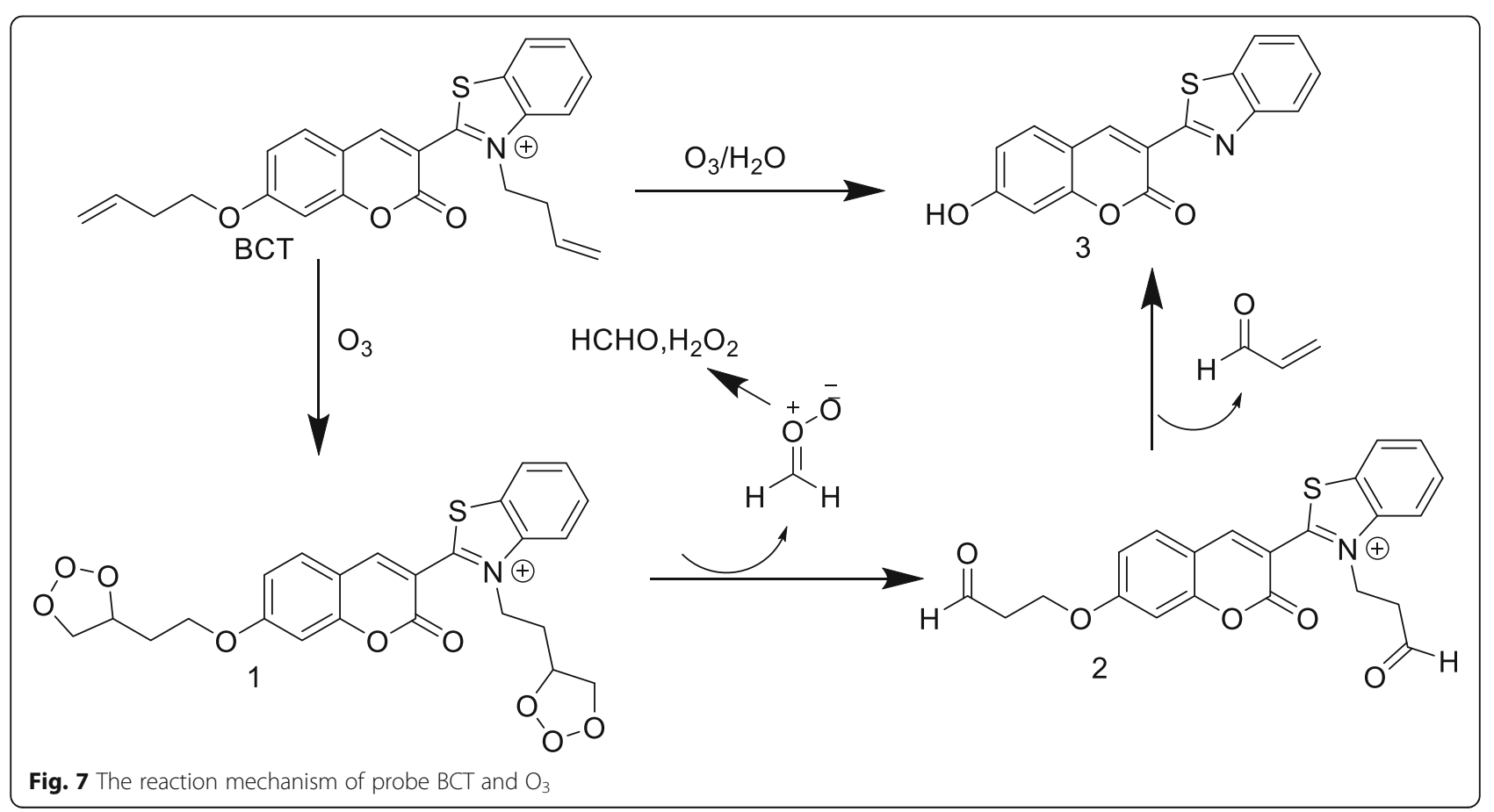


of Science and Technology, Hunan, China. All data can be obtained from the corresponding author (Professor Li Heping) of the manuscript. Research data has been provided in the manuscript and supporting information files.

\section{Abbreviations}

$\mathrm{O}_{3}$ : Ozone; BCT: 3-(but-3-en-1-yl)-2-(7-(but-3-en-1-yloxy)-2-oxo-2H-chromen-3yl)benzo[d]thiazol-3-ium; LOD: Detection limit; PET: Photo-induced electron transfer; IDs: Indigo-5, 5-disulfonate; BDD: Boron-doped diamond; PBS: Phosphate buffered saline; ROS: Reactive oxygen species; $\mathrm{H}_{2} \mathrm{O}_{2}$ : Hydrogen peroxide; $\mathrm{NaClO}$ : Sodium hypochlorite; TBHP: Tert-butyl hydroperoxide; $\mathrm{O}_{2}{ }^{-}$: Superoxide anion radical; $\mathrm{KO}_{2}$ : Potassium peroxide; DMSO: Dimethyl sulfoxide; ${ }^{1} \mathrm{O}_{2}$ : Singlet oxygen; $\cdot \mathrm{OH}$ : Hydroxyl radical; Fe(II)EDTA: Sodium iron ethylenediaminetetraacetate; UV-vis: Ultraviolet absorption spectrum; TMS: Tetramethylsilane; ${ }^{1} H$ NMR: Hydrogen nuclear magnetic resonance; HRMS: High-resolution mass spectrum;

DMF: Dimethylformamide; $\mathrm{K}_{2} \mathrm{CO}_{3}$ : Potassium carbonate; EtOAc: Acetic acid; $\mathrm{Na}_{2} \mathrm{SO}_{4}$ : Sodium sulfate; ${ }^{13} \mathrm{C}$ NMR: Carbon nuclear magnetic resonance; $\mathrm{COCl}_{3}$ : Deuterated chloroform; $\mathrm{NaOH}$ : Sodium hydroxide; $\mathrm{HCl}$ : Hydrogen chloride; $\mathrm{MeOH}$ : Methanol; EtOH: Ethanol; $\mathrm{Na}^{+}$: Sodium ion; $\mathrm{K}^{+}$: Potassium ion; $\mathrm{Ca}^{2+}$ : Calcium ion; $\mathrm{Cu}^{2+}$ : Copper ions; $\mathrm{Fe}^{3+}$ : Iron ion;

$\mathrm{ONOO}^{-}$: Peroxynitrite anion; $\mathrm{H}_{2} \mathrm{O}_{2}$ : Hydrogen peroxide; $\mathrm{ClO}^{-}$: Hypochlorite ion; NO: Nitric oxide; GSH: Glutathione; Cys: Cysteine; HBr: Hydrogen bromide

\section{Supplementary Information}

The online version contains supplementary material available at https://doi. org/10.1186/s40543-021-00269-3.

Additional file 1 The following information is available in the supplementary material: Synthesis method of probe BCT and its intermediates; HRMS spectrum of probe BCT (Figure S1); ${ }^{1} \mathrm{H}$ NMR spectrum of probe $\mathrm{BCT}$ in $\mathrm{CDCl} 3$ (Figure S2); ${ }^{13} \mathrm{C}$ NMR spectrum of probe $\mathrm{BCT}$ in $\mathrm{CDCl} 3$ (Figure $\mathbf{S 3}$ ).

\section{Acknowledgements}

Not applicable.

\section{Authors' contributions}

CZ synthesized the probe BCT. YL and JS were mainly responsible for the characterization of BCT. KC was responsible for data collection and analysis and article writing. $\mathrm{HL}$ was the corresponding author. All authors read and approved the final manuscript.

\section{Funding}

This study was supported by the Open Fund of Key Laboratory of Road Structure and Material of Ministry of Transport (kfj170301), Hunan Provincial Natural Science Foundation of China (2019JJ40295), Changsha University of Science and Technology Postgraduate Research and Innovation Project (CX2019SS31), and Key Project of Hunan Provincial Education Department of China (17A002).

\section{Availability of data and materials}

All data generated or analyzed during this study are included in this published article and its supplementary information files.

\section{Declarations}

\section{Competing interests}

The authors declare that they have no competing interests.

\section{Author details}

${ }^{1}$ School of Chemistry and Food Engineering, Key Laboratory of Road Structure and Material of Ministry of Transport, Changsha University of Science and Technology, No.960, Wanjiali South Road, Tianxin District, Changsha City 410114, Hunan Province, China. ${ }^{2}$ School of Hydraulic Engineering, Changsha University of Science and Technology, No.960,
Wanjiali South Road, Tianxin District, Changsha City 410114, Hunan Province, China.

Received: 6 December 2020 Accepted: 23 March 2021

Published online: 07 April 2021

References

Baysan A, Lynch E. The Use of ozone in dentistry and medicine. Primary Dental Care. 2005;12(2):47-52. https://doi.org/10.1308/1355761053695158.

Boeniger MF. Use of ozone generating devices to improve indoor air quality. Am Industrial Hygiene Assoc J. 1995;56(6):590-8. https//doi.org/10.1080/15428119591016827.

Fan J, Hu M, Zhan P, Peng X. Energy transfer cassettes based on organic fluorophores: construction and applications in ratiometric sensing. Chem Soc Rev. 2013:42:29-43.

Fang WL, Tang YJ, Guo XF, Wang $H$. A fluorescent probe for carbon monoxide based on allyl ether rather than allyl ester: A practical strategy to avoid the interference of esterase in cell imaging. Talanta. 2019;205:120070. https://doi. org/10.1016/j.talanta.2019.06.070.

Garner AL, St Croix CM, Pitt BR, Leikauf GD, Ando S, Koide K. Specific fluorogenic probes for ozone in biological and atmospheric samples. Nat Chem. 2009; 1(4):316-21. https://doi.org/10.1038/nchem.240.

Ishii Y, Ivandini TA, Murata K, Einaga Y. Development of Electrolyte-Free Ozone Sensors Using Boron-Doped Diamond Electrodes. Anal Chem. 2013;85:42848. https://doi.org/10.1021/ac400043b.

Kettle AJ, Clark BM, Winterbourn CC. Superoxide Converts Indigo Carmine to Isatin Sulfonic Acid. J Biol Chem. 2004;279(18):18521-5. https:/doi.org/10.1074/jbc.m400334200.

Kim, Alexis NE, Rappold AG, Kehrl H, Hazucha MJ, Lay JC, et al. Lung Function and Inflammatory Responses in Healthy Young Adults Exposed to $0.06 \mathrm{ppm}$ Ozone for 6.6 Hours. Am J Respir Crit Care Med. 2011;183(9):1215-21. https:// doi.org/10.1164/rccm.201011-1813oc.

Leslie AK, Li D, Koide K. Amine-Promoted $\beta$-Elimination of a $\beta$-Aryloxy Aldehyde for Fluorogenic Chemodosimeters. J Organic Chem. 2011;76(16):6860-5. https://doi.org/10.1021/jo200947e.

Li Z, Li X, Gao X, Zhang Y, Shi W, Huimin MA. Nitroreductase Detection and Hypoxic Tumor Cell Imaging by a Designed Sensitive and Selective Fluorescent Probe, 7-[(5-Nitrofuran-2-yl)methoxy]-3H-phenoxazin-3-one. Anal Chem. 2013;85:3926-32. https://doi.org/10.1021/ac400750r.

Liao Y-C, Venkatesan P, Wei LF, Wu SP. A coumarin-based fluorescent probe for thiols and its application in cell imaging. Sensors and Actuators B: Chemical. 2016;232:732-7. https://doi.org/10.1016/j.snb.2016.04.027.

Nam Y, Kim BS, Shin I. Highly sensitive and selective bioluminescence based ozone probes and their applications to detect ambient ozone. Chem Commun. 2016;52(6):1128-30. https://doi.org/10.1039/c5cc08622a.

Oyama ST. Chemical and catalytic properties of ozone. Catalysis Rev. 2000;42(3): 279-322. https://doi.org/10.1081/CR-100100263.

Sun W, Li W, Li J, Zhang J, Du L, Li M. A benzothiazole-based fluorescent probe for thiol bioimaging. Tetrahedron Lett. 2012;53:2332-5. https:/doi.org/10.1016/j.tetlet.2012.02.098.

Takeuchi K, Ibusuki T. Quantitative determination of aqueous-phase ozone by chemiluminescence using indigo-5,5'-disulfonate. Anal Chem. 1989;61(6):619_ 23. https://doi.org/10.1021/ac00181a025.

Wang K, Lai G, Li Z, Liu M, Shen Y, Wang C. A novel colorimetric and fluorescent probe for the highly selective and sensitive detection of palladium based on $\mathrm{Pd}(0)$ mediated reaction. Tetrahedron. 2015;71(41):7874-8. https://doi.org/1 0.1016/j.tet.2015.08.021

Wentworth P Jr, McDunn JE, Wentworth AD, Takeuchi C, Nieva J, Jones T, et al. Evidence for Antibody-Catalyzed Ozone Formation in Bacterial Killing and Inflammation. Science. 2002;298(5601):2195-9. https//doi.org/10.1126/science.1077642.

Wentworth P Jr, Nieva J, Takeuchi C, Galve R, Wentworth AD, Dilley RB, et al. Ozone and Atherosclerosis. Science. 2003;302:945-7. https://doi.org/10.1126/ science.302.5647.945 k.

Yan Y, Krishnakumar S, Yu H, Ramishetti S, Deng L-W, Wang S, et al. Nickel (II) Dithiocarbamate Complexes Containing Sulforhodamine B as Fluorescent Probes for Selective Detection of Nitrogen Dioxide. J Am Chem Soc. 2013; 135(14):5312-5. https://doi.org/10.1021/ja401555y.

Zhao C, Shang JY, Yang CS, Li ZW, Ning JH, Li HP. A Water-soluble fluorescent probe for rapid detection of sulfur dioxide derivatives. Anal Sci. 2020;36(3): 329-33. https://doi.org/10.2116/analsci.19P314.

\section{Publisher's Note}

Springer Nature remains neutral with regard to jurisdictional claims in published maps and institutional affiliations. 